\title{
SABERES INY DA ALDEIA DE BURIDINA
}

Pesquisadores de Buridina:

Mariana Malurrereru Karajá Orientadora de Estudo

Alzira Mauri Karajá Professora Alfabetizadora

Ijararu Gedeon Karajá Professor Alfabetizador

Maria Elieta Mauri Karajá Professora Alfabetizadora

Valdirene Leão Gomes Karajá Professora Alfabetizadora

Viviane Ferreira Leão Karajá Professora Alfabetizadora

\section{RESUMO}

São os avós e os pais que escolhem o noivo ou a noiva ainda criança. Depois de casado o rapaz recebe os ensinamentos dos tios e dos avós para caçar, pescar e fazer roça. Depois de casado o casal passa a morar na casa da noiva. A família da noiva passa a ter responsabilidade sobre o casal, até as famílias do casal construírem um rancho para o casal morar. Depois de morar juntos o casal não depende mais das famílias.

PALAVRAS-CHAVE: Noivo. Criança. Família. Avós e pai. 


\section{TURYBÈNABUTẼ}

Heri bdèdỹỹnanaki hỹỹna bdeu, iny lahi, iny tby boho bdè riywinymyhỹre ijadòmahakỹ, weryrybòhòkỹ roikremy itmyraule hèka bdè riywinymyhỹre, hãrabièmy tahè raninimyhỹre. Roimyhỹreu hãbu wèrbi ilanahakỹ, ilabry aõbo, ilabiè boho ritohonymyhỹre, wyhyna, riuna, oworu rèlèmyhỹre bdèdỹỹnanamy. Tasỹ hãbu tahãwyy heto-ò ramyhỹre tai rasỹnymyhỹre tii wna. Irbi tahè heto ixidèè riwinymyhỹre. Myhèka Iny juhu rỹira.

\section{CASAMENTO INY}

São os avós e os pais que escolhem o noivo ou a noiva ainda criança. Depois de casado o rapaz recebe os ensinamentos dos tios e dos avós para caçar, pescar e fazer roça. Depois de casado o casal passa a morar na casa da noiva. A família da noiva passa a ter responsabilidade sobre o casal, até as famílias do casal construírem um rancho para o casal morar. Depois de morar juntos o casal não depende mais das famílias.

\section{HÃRABIÈ-MY HERI}

Weryrybò hèka dèlètyhymy ijadòma wna roimyhyre-u, ilabry ilana boho idi ròimyhyre isionhidyymy, waximy, riumy, oworumy. Weryrybò hèka hãrabièmy radymyhyre, ilana hèka ridymyhyre tòti tyrèki.Weryrybò hèka dèlètyhymy ijadòma wna roimyhyre-ù, tariòrè lahi heto-ki rasynymyhyre tahãwyy wna, irbi tahè ilabry, ilana, isè riòrè boho iheto riwinymyhyrènyre, iriòrè lahi heto birèki. Ihetorèny riwinydi tahè hitximy rasynymyhyrènyre taheto rènyki, irbi tahè tki boho isidirèny ròrènymyhyrenyrè. 


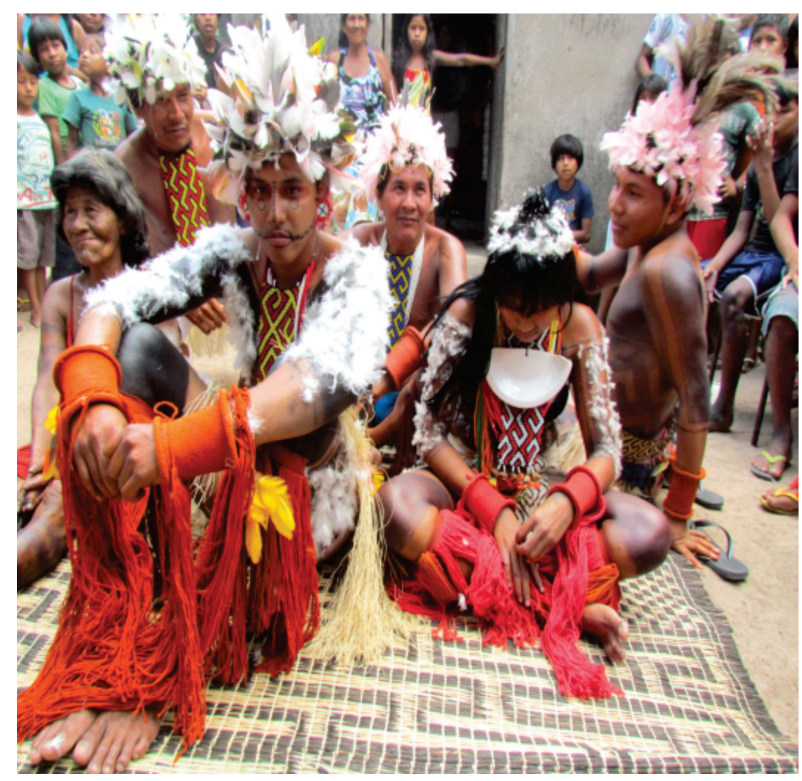

HÃRABIÈ-MY HERI

\section{GRAVIDEZ}

$\mathrm{Na}$ gravidez a mulher é tratada com todo cuidado, carinho e respeito. No sexto mês de gestação não pode ter relação sexual, tem que ficar de repouso para garantir a saúde da criança e da mãe. Depois do parto a mulher volta à vida sexual ativa com um mês e 15 dias. Quando chega a hora do nascimento, os pais e os avôs chamam a parteira. O parto é feito em cima de uma esteira de palha. Depois do parto a família agradece dando de presente esteira, canoa, óleo de tucum etc.

Depois de nascida a pessoa mais experiente da aldeia dá um banho nele com água morna, e, depois do banho, os avós passam urucum na criança para poder limpar a pele, e evitar micose. Nesse período a mãe não pode comer carne e nem peixe, somente canjica de milho, mandioca, e arroz. A mãe fica de repouso durante um mês e 15 dias. O pai fica aguardando o umbigo da criança cair. Depois que cai o pai tem que ser pintado com a tinta de urucum no corpo inteiro, e arranhar com dente de peixe cachorra (latxi). 


\section{BTÒ}

Btò ù kèka hãwyy dèrinamy ryirèrimyhyre, sõèmy raaõmysydyynyõmyhyre rawèbinadunyhèny. Hãwyy rèamyhyreu tahè dèbò ò sohoji reuròmy ahãdu sõè, hãwyy tahãbu wna widèè raaõòtaõmyhyre, sohoji ahãdu wèèrè rimydi tahè isinamy hãwyy tahãbu wna widèè raaõòtamyhyre. Btò ramytxitximyhyre-ù isè, ilabtèry, ilahi boho sadyydu-ò ròimyhyre riijradyynykremy. Btò hèka byyrè tyrèki rèamyhyre, rèamyhyre-u tahè rasbèdyymyhyre hãwyy dèla ityhymy, iijytèõmy ryirahèka hèka risbènymyhyre, iwsè rarekremy ityhymy, iijytèõmy. Isbèdyy rahudi tahè riysinymyhyre waòrnydi, jutà-jutà lau tasy tule idè ryranykremy. Sadyydu hèka raòwydyymyhyre aõtxile aõmy tari, byyrè, yda hãwò aõbo. Tohouã sè hèka rènarèhèmyhyre utura, iròdu-dè riròõmyhyre, iwèruleta imonare mai, ajiura, maixmo iwèrumy riõrèrimyhyre. Tohouã sè hèka sohoji ahãdu wèèrèmy rènarèhèmyhyre, irbi tahè ixinamy byrènatyhy rirsymyhyre. Tohouã tby tahè tariòrè binoti isena, riraòmy runyrèrimyhyre, iriòrè binoti rèsèrahudi tahè tohouã tby rahemyhyre latximy, tasy tule aysidyymyhyre waòrny-di. Ijèsudu hèka tohouã tby rihèmyhyre iwsèmy rarekremyijèsudumy.

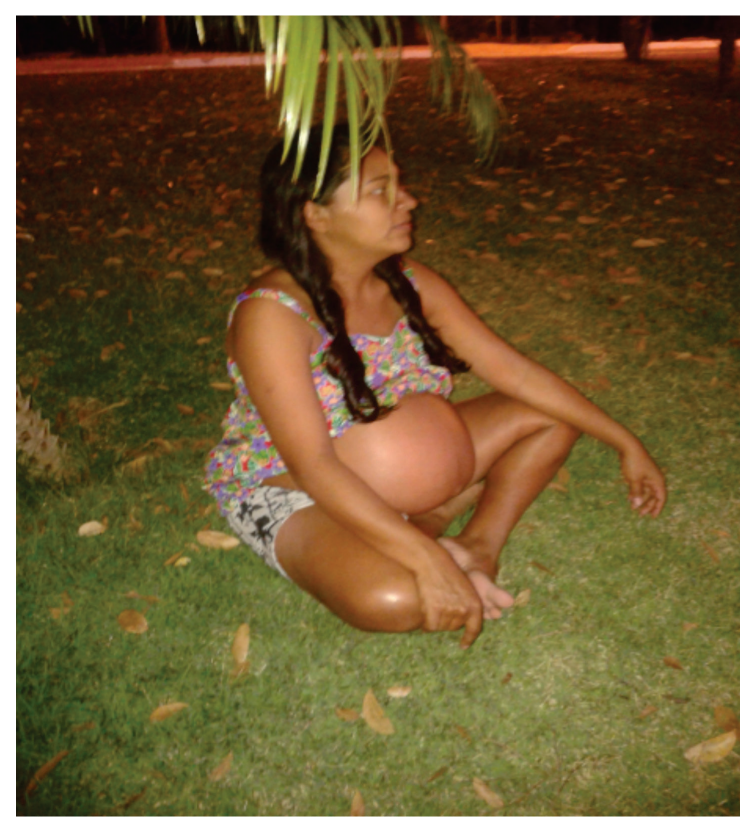




\section{BTÒ}

\section{CRESCIMENTO (SEXO FEMININO)}

\section{IDADE 03 A 07 ANOS}

Essa é uma fase de curiosidade, muita brincadeira e aprendizagem. As meninas brincam de boneca de barro e madeira, feita pela mãe ou avó. Sempre juntas da mãe ou avó, as meninas brincam somente com as meninas.

\section{INY HIRARI}

Inataõ, dèbò ò inatxi reuròmy iwyrarèny.

Hirari boho hèka tsinarèny sõèrènyre, suu ritxoo, òwòrulyri ritxoo, ruu wèbò my hèka tsinarènyre. Ilahi, isè, ilajirà boho hèka iritxoo tamyrèny riwinymyhyre, hirari boho hèka wiwna rsinymyhyrènyre weryry wna aõkõ, tasy tule irèhèmy rsinyrènyõmyhyre tadi rbi, tadi birèkile rsinymyhyrènyre. Alsi rbi hky tahè hirari boho roèrymyhyrenyre, timybo uladu-sè tariòrè-di ryirèrimyhyre.

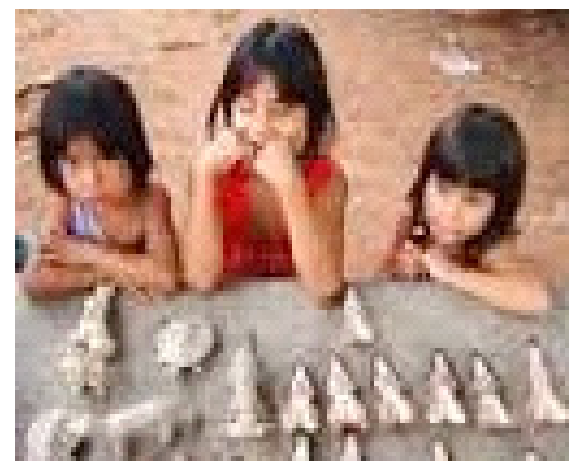

INY HIRARI

\section{CRESCIMENTO (SEXO MASCULINO)}

\section{IDADE 03 A 07 ANOS}

Essa é uma fase de curiosidade, muitas brincadeiras e 
aprendizagem. Os meninos brincam de arco e flecha, onça, gavião, pato, nadar no rio, caça e pesca, corrida de coxinho, luta de corpo, pega-pega no rio. $\mathrm{Na}$ cultura indígena, foram incluídas novas brincadeiras tais como bolinha de gude, futebol, pula corda.

\section{INY WERYRY}

Iny weryry hèka tsinarèny sõere, wyhy-di dehu, hãwò-di lowo, nawiihikymy lsi, hèlyyrèmy lsi, alobu, ijesu, mny mny, hãlòè my lsi, riumy lsi, waximy lsi.Wiji bdèmy hèka Iny weryryrèny-ò sõèmy lsina rexihonymy ryira tori rbi trywè-di dehu, òtèti-di isidy, bètèa-di dehu.

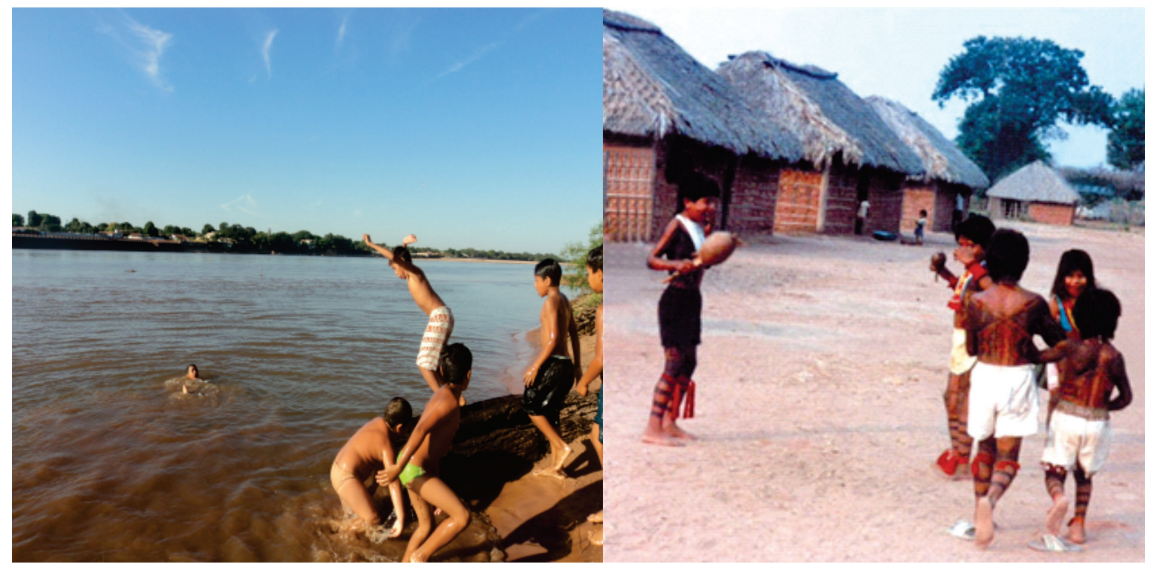

INY WERYRY

\section{NA FASE DA ADOLESCÊNCIA (FEMININA)}

\section{PERÍODO ENTRE 08 AOS 12 ANOS}

Nesse período a moça está pronta para menstruar. A moça fica somente no quarto fechado, durante o período menstrual. Isso acontece só no primeiro ciclo menstrual da moça, e seu alimento é canjica de milho e arroz. Depois do término da menstruação o pai e os tios vão pescar para festejar junto com a comunidade. A moça está pronta para dançar na festa tradicional, anunciando sua nova fase de moça e pronta para se casar. 


\section{DÈLÈTYHYMY RAIJADÒMANYMYHYREU}

Dèbò ò inaubiòwamy hirari tawyradi ryirèrimyhyre, hirarimy ranidyymyhyre, dèbò wiòmy wyra rimydi tasy, hirarihikymy ranidyymyhyre, waò inatxi reuròmy tasy ijadòmamy ranidyymyhyre. Hirarihiky hèka dèlètyhymy raijadòmanymyhyreu, hetowoki runyrèrimyhyre tèytna riraòmy. Ijadòma hèka utura iròdu-dè riròõmyhyre, maixmo iwèru, mai iwèrule tahè imõnare, rèytymyhyreu tahè aõtxile Iny rsyna rirsymyhyre. Ijadòma hèka rèytykre okotyrè ilana, ilabry, ilabiè, iseriòrè boho ròimyhyre tèytyna itxèmy, waximy tasy tule riumy. Iny aõdudumy ryira hèka ijdòma ritèytynymyhyre hãwòdu, oworudu, riudu, ijèsudu, hãwyyra wna byyrèdu, yridu, hèradu, ijyydu, tasy tule iòsi riòròlemyhyre. Rèytymyhyreu tahè sõèmy Iny mahãdu rotymyhyre bròtyrèmy, Iny hèka aõtxile rabròtyrèmyhyre hãwo, oworu, byyrè, tari, owoji, narihi butumy Iny aõmydyynamy rabròtyrèmyhyrenyre. Ijadòma hèka iruxeramy ròhònymyhyre ixy mahãdu itxèrènamy rexiywinymy. Tasy tule ijadòma tõhõdimy ryirèrimyhyre, hàri hèka ijasò tõhõmy riòturòsòdyynymyhyre, tusinamy dori. Hàri hèka ijasò bèra rbi ridymyhyre, tasy tule itàti rbi ridylemyhyre.

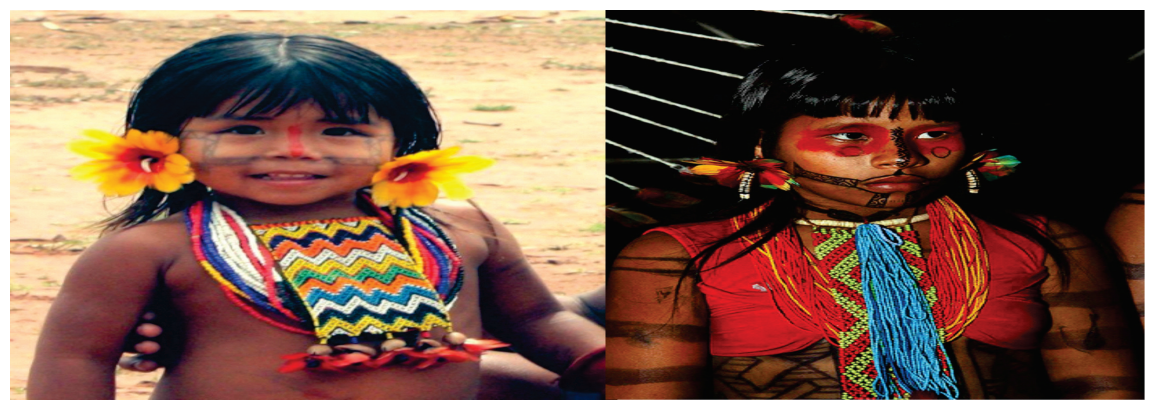

DËLÊTYHYMY RAIJADÒMANYMYHYREU

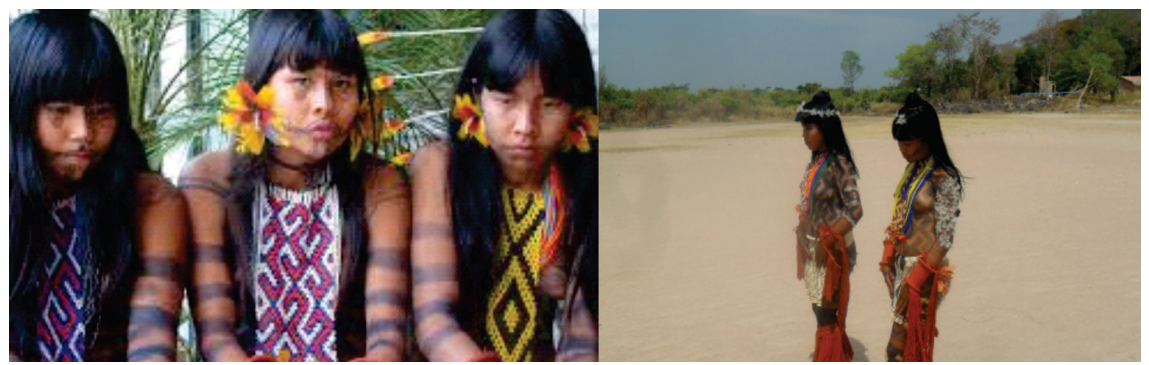




\section{IDOSO}

As pessoas que nós nos tornamos hoje são resultados do que nos foi ensinado, quando ainda estávamos aprendendo a viver. Tudo que vivemos, o que somos, o que seremos e até o que não fomos devemos agradecer a essas pessoas maravilhosas que são nossos avôs e pais. Eles que dedicaram sua vida para ensinar com carinho, dedicação e muito amor. Deitados em uma esteira de palha, olhando para o céu contavam história da grande estrela (Takinahakỹ), ou andando na floresta, coletando frutas, pescando, procurando ovos de tartaruga na praia. Esses valores e muitos outros foram passados com muito amor.

\section{LABIKÈ LAHI WNA}

Lahi labikè boho hèka awi roire rarudènaki, ijkyduki, tasy tule dohokudkyduki awi roire. Labikè lahi boho hèka sõèmy taritxòrè, taritxokorè boho ritohokunymyhyre kywimy roirekremy, èhèhèkõmy, wasikõmy, taikumy rityhynymy roirekremy. Lahi labikè boho hèka rukumy ijkymy relkymyhyrènyre taritxokorè boho koku bkyrè tyrèki. Sõèmy hèka Iny ijky ryira Takinahakỹmy ijky, koboi my ijky, woku my ijky, krysa my ijky, kralahu my ijky, ihãrèta sõèmy ryira Iny ijky. Taiki tahè ritxokorè, ritxòrè boho sõèmy talahi, talabikè bohomy rèrinamyhyre, iwse tki boho taritxokorè, taritxòrè bohomy rèrinanymyhyrènyre wsè. Senadu matukari boho hèka ratyhydyymyhyre, tkièmy dokori tki boho dohokudkydu roire,tasy tule rarudèna roire.

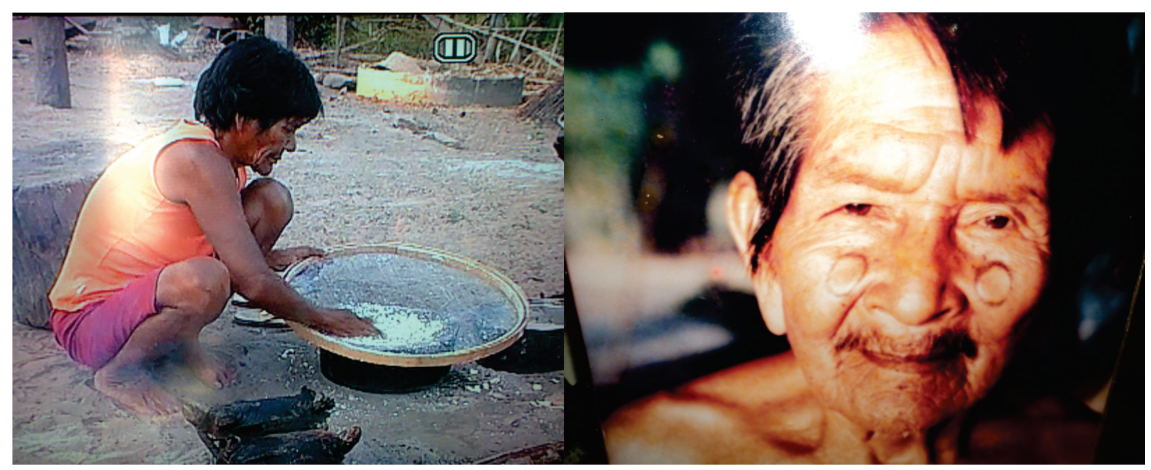




\section{LABIÈ LAHI WNA}

Isto é um pouco da pesquisa que nós professores/ pesquisadores da Escola Indígena Maurehi, da aldeia de Buridina, fizemos. Esta pesquisa representou muito para nós, fortaleceu o 'Projeto de Educação e Cultura Indígena Maurehi', que visa a re/ vitalização dos saberes Iny, em Buridina. 